\title{
PHILATELY AND RADIOLOGY
}

\section{Rishabh Kapila ${ }^{1}$, BV Subash ${ }^{1}$}

${ }^{1}$ International Research Fellow, Showa University School of Dentistry, Tokyo, Japan.

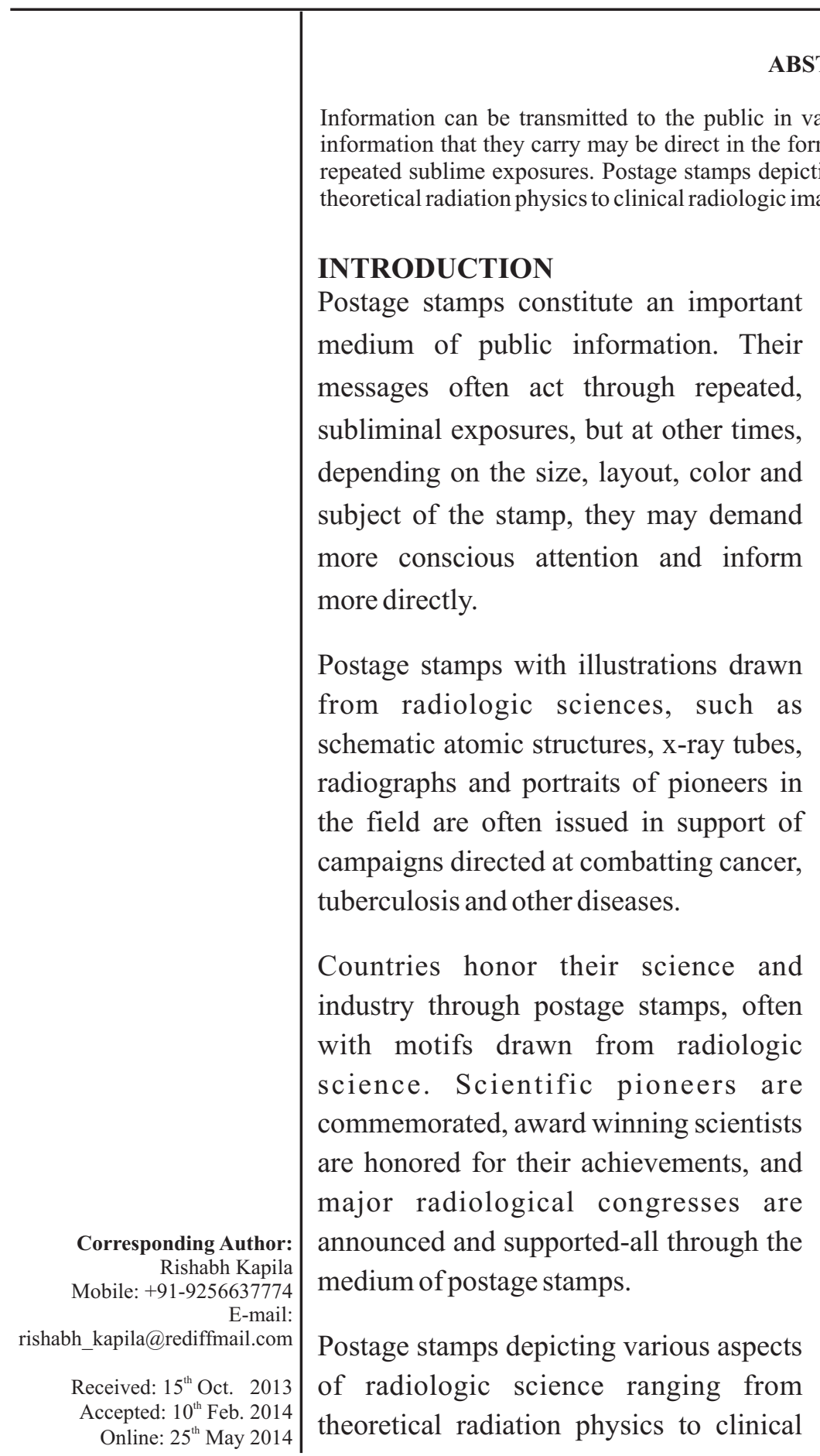

radiologic imaging and treatment are illustrated in this article.

\section{WILHELM CONRAD ROENTGEN}

W.C. Roentgen was a German physicist (1845-1923). During experiments with a Crookes' vacuum tube, he discovered an unknown radiation on 8 November, 1895. He named his discovery $\mathrm{x}$ rays and almost completely described their physical properties in a paper published in January 1896. ${ }^{1}$ The abilities of $\mathrm{x}$-rays to penetrate solid bodies and to blacken photographic emulsions are fundamental to diagnostic radiology.

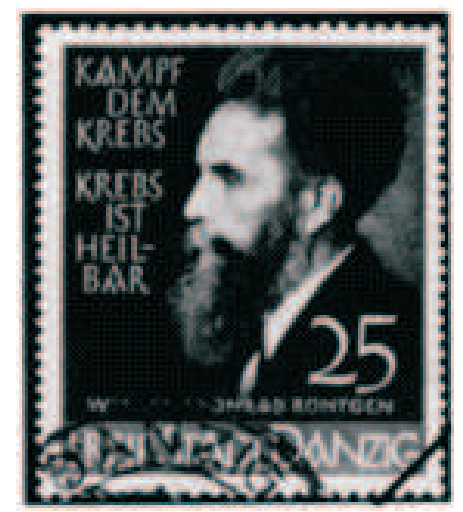

On the occasion of an anti-cancer campaign, W.C. Roentgen was first portrayed on a postage stamp, Danzig, 25 pf, 1939. 


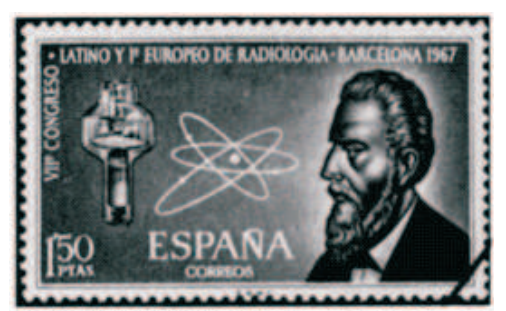

Roentgen was portrayed with an x-ray tube and the atomic symbol on the occasion of the First European Congress of Radiology, Barcelona. Spain, 150 ptas, 1967.

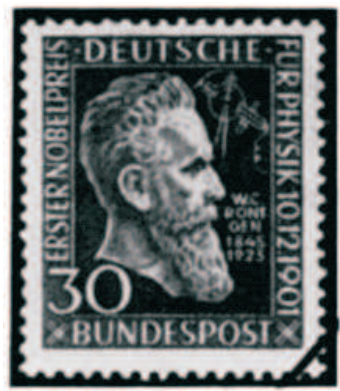

Roentgen was commemorated on the 50th anniversary of his Nobel Prize in the German Federal Republic, 30 pf, 1952. ${ }^{2}$

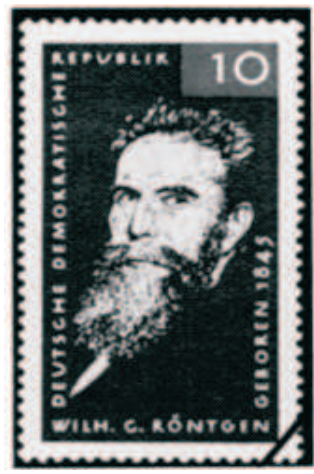

The 120th anniversary of Roentgen's birth was commemorated by the German Democratic Republic, $10 \mathrm{pf}, 1965 .^{3}$

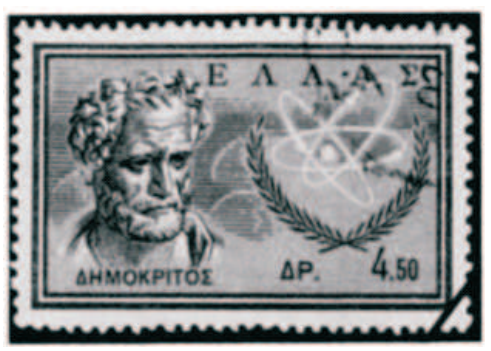

About 400 BC, the Greek philosopher Democritos assumed that substances were composed of indivisible particles and named them atoms after the Greek word atomos: indivisible. Greece, $4.50 \mathrm{dr}, 1961$.
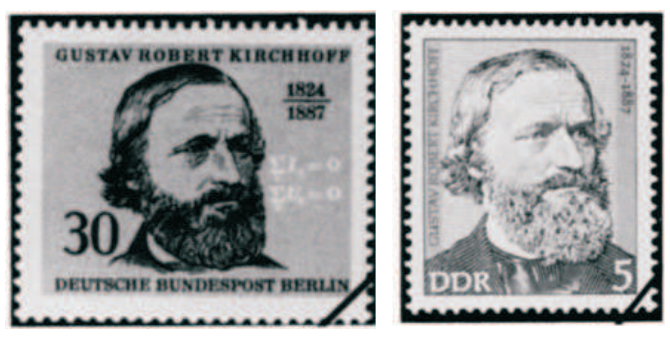

Gustav R. Kirchhoff, a German physicist (1824-1887) together with R. Bunsen discovered a characteristic emission of light from glowing chemical elements. They made the identification of elements possible by spectral analysis. Kirchhoff was commemorated on the 150th anniversary of his birth with two issues: Federal Republic of Germany, Berlin, 30 pf, 1974, German Democratic Republic, 5 pf, 1974.

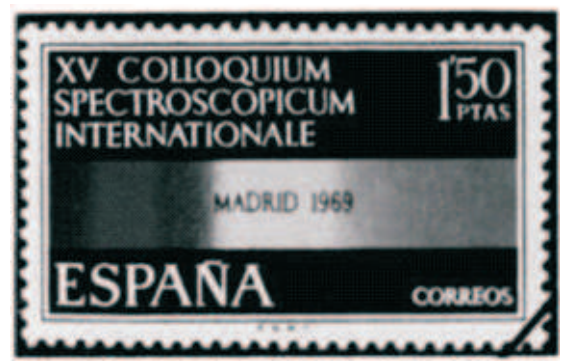

A spectrum is shown on a stamp announcing the XV Colloquium Spectroscopicum Internationale, Madrid, Spain, 1.50 pts, 1967.

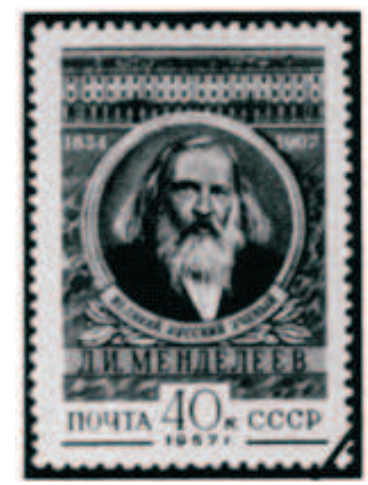

Dmitri Ivanavitch Mendeleiev, Russian chemist (1834-1907) formulated the "periodic law" stating that the properties of chemical elements recur periodically when the elements are arranged in order of their atomic weights. Mendeleiev was commemorated on the 50th anniversary of his death, Soviet Union, 40 k, 1957. 


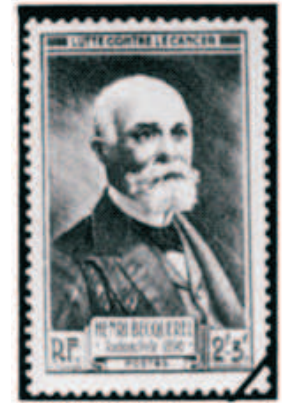

In 1896, the year after Roentgen's discovery of x-rays, Henri Becquerel, a French physicist (1852-1908), discovered a spontaneous radiation from uranium. ${ }^{4} \mathrm{~A}$ stamp with Becquerel's portrait supported an anticancer campaign in France, 2+3 f, 1946.

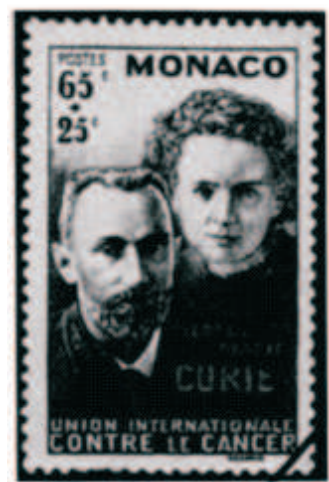

Marie and Pierre Curie together discovered two strongly radioactive elements, polonium and radium in 1898. Their portraits support many anti-cancer campaigns. Monaco, 65+25 c, 1938.

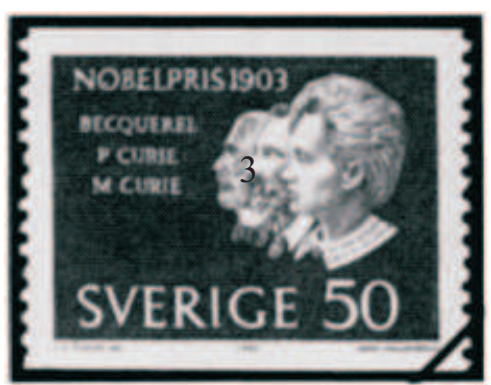

The Nobel Prize in Physics for 1903 was awarded to Becquerel for the "discovery of spontaneous radioactivity" and to Marie and Pierre Curie for "work on the radiation phenomena discovered by Becquerel". ${ }^{5}$ Sweden, 50 ore, 1963.

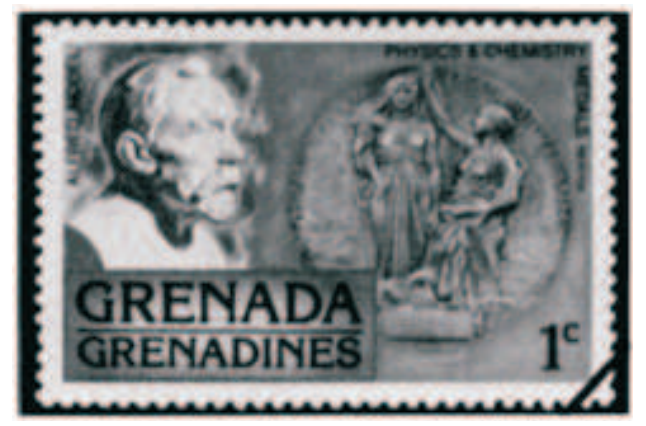

The Nobel Prize is often mentioned in this series of famous scientists. Alfred Nobel was a Swedish chemist and inventor (1833-1896). He described a technique of controlled detonation of nitroglycerine. Before his death, he established the Nobel Foundation in 1895. Nobel's portrait and the reverse of the Nobel medal for physics and chemistry are shown on this stamp from Grenada, Grenadines, 1 c, 1978.

\section{REFERENCES}

1. Knutsson F, Roentgen and the Nobel Prize. With notes from his correspondence with Svante Arrhenius. Acta Radiol Diag 1969;8:449-460.

2. Knutsson F, Roentgen and the Nobel Prize. The discussion at the Royal Academy of Sciences in Stockholm in 1901. Acta Radiol Diagn 1974:15:465-473.

3. Roentgen WC. Ueber elne neue Art von Strahlen. Sitzungsberichteder Physik-Med. Gesellschaft zu Wurzburg 1896;132-141.

4. Becquerel AH. Sur quelques propriete nouvelles des radiations invisibles emises par divers corps phosphorescents. CR Acad Sci (Paris) 1896. p.122, 559.

5. Knutsson F. Becquerel and the discovery of radioactivity. Acta Radiol Diagn 1975:16:113-116. 